NBER WORKING PAPER SERIES

\title{
PUBLIC GOODS PROVISION IN THE PRESENCE OF HETEROGENEOUS GREEN PREFERENCES
}

\author{
Mark Jacobsen \\ Jacob LaRiviere \\ Michael Price \\ Working Paper 20266 \\ http://www.nber.org/papers/w20266
}

\author{
NATIONAL BUREAU OF ECONOMIC RESEARCH \\ 1050 Massachusetts Avenue \\ Cambridge, MA 02138 \\ June 2014
}

The authors did not receive direct financial support for this research nor do they have outside financial relationships that are relevant to the research. The views expressed herein are those of the authors and do not necessarily reflect the views of the National Bureau of Economic Research.

NBER working papers are circulated for discussion and comment purposes. They have not been peerreviewed or been subject to the review by the NBER Board of Directors that accompanies official NBER publications.

(C) 2014 by Mark Jacobsen, Jacob LaRiviere, and Michael Price. All rights reserved. Short sections of text, not to exceed two paragraphs, may be quoted without explicit permission provided that full credit, including $(\mathcal{C}$ notice, is given to the source. 
Public Goods Provision in the Presence of Heterogeneous Green Preferences

Mark Jacobsen, Jacob LaRiviere, and Michael Price

NBER Working Paper No. 20266

June 2014

JEL No. D03,D04,H41,Q48

\section{ABSTRACT}

We develop a model of the private provision of public goods in a world where agents face convex costs of provision. Consonant with prior empirical evidence, we introduce preference heterogeneity by allowing a subset of agents to exhibit pro-social behavior that reflects "green" preferences. We use the model to compare different policies to promote private provision of public goods such as environmental quality or energy conservation. Counter to the standard result, we find that technology standards are frequently preferred to price-based instruments. Extending the model to allow for both benefit and cost heterogeneity, we find that policy choice depends on the correlation between the two forms of heterogeneity.

Mark Jacobsen

Department of Economics, 0508

University of California, San Diego

9500 Gilman Drive

La Jolla, CA 92093

and NBER

m3jacobs@ucsd.edu

Jacob LaRiviere

Department of Economics

University of Tennessee

525 Stokely Management Center

Knoxville, TN 37996-0550

jlarivi1@utk.edu
Michael Price

Department of Economics

Andrew Young School of Policy Studies

Georgia State University

P.O. Box 3992

Atlanta, GA 30302-3992

and NBER

mprice25@gsu.edu 


\section{Introduction}

The federal government recently passed legislation placing a minimum standard on lighting that would ultimately ban the sale of standard incandescent lightbulbs. Viewed through the lens of the standard economic model, such a policy is typically inefficient relative to price-based alternatives that tax the sale of incandescent bulbs or subsidize the purchase of energy-saving bulbs like compact fluorescents and LEDs. We develop a model of the private provision of public goods that results in cost rankings counter to this traditional wisdom. Specifically, we consider an economy where agents are heterogeneous in the value they place on an underlying public good and derive conditions under which the costs of achieving any given level of provision are lower under technology standards or mandates such as the ban on incandescent lighting. We motivate our model with examples from energy and environmental policy and explore how preference heterogeneity impacts the choice of regulatory instrument. In doing so, we highlight a potential role for mandates such as minimum standards on energy efficiency or fuel economy.

There is a vast literature exploring the private provision of public goods and the underlying motivation for charitable behaviors. The canonical approach to modeling the private provision of public goods is to assume that individuals give because they receive benefit from the act of giving itself. ${ }^{1}$ We build on this literature and develop a model of the private provision of public goods where individuals are permitted to value public goods heterogeneously.

Our focus on preference heterogeneity for energy efficiency accords well with prior studies showing that individuals differ in their willingness to pay for energy saving technologies (e.g., Saphores, Nixon, Gounseitan, and Shapiro (2007), Kotchen and Moore (2007) and Jacobsen (2013)) and/or willingness to take costly actions to conserve resources to improve

\footnotetext{
${ }^{1}$ Becker (1974) provides perhaps the earliest treatment of such preferences and shows how charitable behavior can be motivated by the desire to receive social acclaim or avoid the scorn of others. More recent manifestations of Becker's approach include Andreoni (1989) and Andreoni (1990) which formalize the "warm glow" model and impurely altruistic motives for giving; Hollander (1990) who focuses on the role of prestige and the desire to earn social approval; Akerlof and Kranton (2000) and DellaVigna, List, and Malmendier (2012) who focus on the role of social pressures; and Glazer and Konrad (1996) and Benabou and Tirole (2006) who focus on self-image concerns and the desire to signal private information to others.
} 
environmental quality (Costa and Kahn (2011), Allcott (2011), Ferraro and Price (2013), Ito, Ida, and Tanaka (2013), or Metcalfe and Dolan (2013)). For example, Saphores, Nixon, Gounseitan, and Shapiro (2007) measure consumer willingness to pay for "greener" cell phones and computers and find that while 30 percent of respondents are unwilling to pay a price premium for such goods, 35 percent of respondents are willing to pay an added premium of up to 10 percent. Poortinga, Steg, Vlek, and Wiersma (2003) report survey data from the Netherlands highlighting significant heterogeneity in attitudes towards various steps individuals could take to reduce their energy consumption and that such heterogeneity is more pronounced for high cost/high benefit actions. ${ }^{2}$

To our knowledge, ours is the first paper to evaluate the efficiency of alternative policy instruments in an economy where heterogeneous agents privately provide some baseline level of the targeted public good. Prior studies consider policy choice in the presence of homogeneous agents that are boundedly rational (Allcott, Mullainathan, and Taubinksy (2012)), face some form of uncertainty (Weitzman (1974), Segerson (1988), or Hoel and Karp (2001)), or are in overlapping regulatory environments (Holland, Hughes, and Knittel (2009) and Holland (2012)). Our model takes an alternate approach. We augment the neoclassical model of public good provision by introducing "green" preference heterogeneity and explore how this impacts private provision and subsequent policy choice.

We develop a model for private provision of public goods with two types of consumers who differ in the value they place on the underlying public good. For example, our model captures an environment where some agents care only about their own returns from the public good while others care not only about their own returns but also those received by others in the economy. ${ }^{3}$ While this heterogeneity in preferences is itself well documented, the implications of allowing for heterogeneous preferences in attendant public goods provision and the design of public policies remain under-researched - a gap in the literature we aim to fill.

\footnotetext{
${ }^{2}$ Similary, Allcott (2011) and Costa and Kahn (2011) find significant heterogeneity across household types in the response to targeted messages designed to promote energy conservation.

${ }^{3}$ In this regard, our model shares similarity with the notion of efficiency preferences in Charness and Rabin (2002) or other models of interdependent preferences such as Levine (1998) or Akerlof and Kranton (2000).
} 
For simplicity we begin with a model where all agents face identical, increasing marginal costs of provision. This structure is well suited to considering household energy conservation but also fits a variety of other policy settings such as the decision to volunteer time or provide pro-bono services. In the context of energy, household choices over electricity use and transportation are natural targets for policy given their large impacts on air pollution and climate. ${ }^{4}$ Individuals wishing to reduce their household energy footprint - either voluntarily or as a result of policy - face rising costs on the margin: we use the specific cases of increased fuel economy in automobiles and energy-efficiency of household durables as motivation below.

Within this simple theoretical framework we first show that agents with pro-social preferences invest more in public good provision. The private equilibrium violates the equimarginal principle and is thus inefficient: pro-socials face a higher marginal cost of provision. We next explore the relative efficacy of two government policies - Pigouvian taxes and minimum standards - designed to promote increased public good provision. Counter to traditional wisdom, we show that the costs of achieving any given provision level are lower under standards than any uniform Pigouvian tax. The intuition for this result is straightforward: uniform taxes/subsidies induce all agents to provide more of the public good and hence preserve the wedge in marginal cost of provision across types. Standards, in contrast, have asymmetric effects across types and serve to equalize the marginal costs of provision. ${ }^{5}$

We next perform comparative statics on key model parameters to identify conditions under which the relative benefits of standards are greatest. Results from this analysis highlight that for any fixed level of provision, the welfare advantage of standards is (i) increasing in the weight "pro-socials" place on the returns to providing the public good and (ii) single-peaked in the proportion of such types in the economy.

Finally, we extend the model to allow cost heterogeneity across the two types of agents. We show that the relative superiority of standards holds if we allow costs to be negatively

\footnotetext{
${ }^{4}$ In the U.S., these household-level choices over energy use account for approximately 40 percent of all greenhouse gas emissions.

${ }^{5}$ To the best of our knowledge, our model is the first to show the superiority of standards absent behavioral anomalies such as hyperbolic discounting or limited attention (see Allcott, Mullainathan, and Taubinksy (2012)).
} 
correlated with preferences for the public good. However, the relative benefit of standards is eroded if cost heterogeneity is otherwise idiosyncratic. Thus in a world with both preference and cost heterogeneity, the preferred policy option depends on the extent of heterogeneity along the various dimensions. Intuitively, greater preference heterogeneity favors a standard whereas (relatively) greater cost heterogeneity favors price-based policies.

While the scope of our model is broad, we frame our discussion in the context of green preferences and the associated provision of environmental goods like energy conservation. Within this realm, our model highlights a somewhat counterintuitive result. In a world with preference heterogeneity and convex costs of provision, uniform price instruments (taxes or subsidies) designed to encourage energy efficiency may prove more costly than technology mandates. For example, if consumers differ in their preferences for clean air then minimum MPG requirements may prove a more efficient way to promote fuel efficiency and reduce greenhouse gas emissions than CAFE standards which introduce a shadow price on fuel economy. Similarly, bans on incandescent light bulbs may prove a more cost effective way to promote energy efficient lighting choices than subsidies on the purchase of CFL or LED bulbs.

The remainder of the paper is organized as follows: section two introduces the theoretical model and derives analytical results. Section three provides an algebraic example of the theoretical model. Section four discusses the theory in the context of light bulb efficiency and automobile choice. Section five concludes.

\section{Public Goods Provision and Green Preferences}

We being by outlining a theoretical model of public goods provision in a world where agents face identical costs of provision but have heterogeneous preferences for the public good. We then analyze the cost of alternative policies designed to promote increased provision in this setting. Section 2.2 extends the model to allow a second form of heterogeneity: differences between agents in the cost of provision. We show how the two sources of heterogeneity compete in determining optimal policy choice. Proofs appear in Appendix A. 


\subsection{Modelling Preference Heterogeneity}

We begin with a simple model of utility over a numeraire private good, $c$ and a public good, $X$. Provision of $X$ will be the sum across $N$ members of the economy where $x_{i}$ is the contribution of the $i$ th member, $\Sigma_{i=1}^{N} x_{i}=X$. Individuals provide the public good subject to a strictly convex cost function $h\left(x_{i}\right)$ with $h^{\prime}\left(x_{i}\right)>0, h^{\prime \prime}\left(x_{i}\right)>0$. We will consider the provision of energy conservation and environmental quality in our examples below, but the setting is generalizable to a broad range of public goods.

The assumption of increasing marginal costs accords well with energy conservation and the associated private provision of environmental quality. For example, in the context of energy conservation provided through lighting choices the switch from incandescent to CFL bulbs may be relatively cheap. However, if an individual wishes to provide even more conservation they may switch to more expensive LED-based products, effectively moving up the marginal cost curve. Similarly, electricity intensive durable goods like washers, dryers, and refrigerators increase in cost as energy efficiency of the product increases. Hence, individuals wishing to reduce their carbon footprint and contribute to environmental quality face the type of cost structure assumed in our model. ${ }^{6}$ We consider other examples and cases where cost heterogeneity also enters in later sections.

Preferences over the two goods will be given by:

$$
\begin{aligned}
& U_{i}\left(c_{i}, X\right)= c_{i}+\tilde{V}_{i} f(X) \\
& \text { s.t. } y_{i}=c_{i}+h\left(x_{i}\right) \\
& \Rightarrow U_{i}\left(c_{i}, X\right)=y_{i}-h\left(x_{i}\right)+\tilde{V}_{i} f(X)
\end{aligned}
$$

In equation (1) utility is assumed linear in the numeraire good and weakly concave in the agent's valuation of the public good. As is standard in the public goods literature, we will assume that $\lim _{x \rightarrow 0} f^{\prime}(X)=\infty$ and $f^{\prime}(X) \geq 0$ for all $X$. We show in appendix B that this

\footnotetext{
${ }^{6}$ Our assumptions in this simple version of the model will be met to the extent consumers face similar costs in the marketplace and the technologies are close substitutes in providing a final good (e.g., household lighting in the case above)
} 
formulation is equivalent to a model with decreasing marginal utility over the consumption good and a linear budget constraint as in other work on the private provision of public goods (e.g., Andreoni (1989)). ${ }^{7}$ The heterogeneity we consider in our model arises through the term $\tilde{V}_{i}$, which scales each agent's preference for the public good. ${ }^{8}$ For simplicity we will allow two types of agents, a share $\alpha$ with $\tilde{V}_{i}>1$ and a share $(1-\alpha)$ with $\tilde{V}_{i}=1$.

In practice, there are several interpretations for heterogeneity in $\tilde{V}$. First, the differences could be due to strict neoclassical preference heterogeneity. Indeed, there is significant field evidence that agents have varying preferences for privately provided public goods (Saphores, Nixon, Gounseitan, and Shapiro (2007) and Kotchen and Moore (2007)) or attitudes towards different strategies that one could take to reduce their energy consumption Poortinga, Steg, Vlek, and Wiersma (2003). ${ }^{9}$ Second, variation in $\tilde{V}$ could possibly embed heterogeneity in marginal benefits for the public good from any source so long as it enters multiplicatively (e.x., social norms as in models described by Benabou and Tirole (2006) or DellaVigna, List, and Malmendier (2012)). ${ }^{10}$ Third, heterogeneity in $\tilde{V}$ allows generalized efficiency preferences, as in Charness and Rabin (2002) or a variant of the warm-glow model whereby agents receive personal benefit from knowing that the public good is provided at some given level rather than simply from the act of giving in and of itself.

\footnotetext{
${ }^{7}$ Hence, our results are not driven by the quasi-linear functional form assumption.

${ }^{8} \mathrm{We}$ assume that the shape of preferences for the public good given in $f(X)$ is common across agents. This assumption is made to simplify the analysis and provide transparency in the associated discussion. However, it is important to note that other sources of heterogeneity can also produce our result provided they introduce differences in marginal benefit across types.

${ }^{9}$ There is also an immense body of evidence from laboratory experiments suggesting heterogeneity in the willingness of individuals to contribute to a group fund. For example, Fischbacher and Gaechter (2008) identifies substantial heterogeneity in people's preferences and shows that the decline in public good provision over time is driven by the fact that many people have a preference to contribute less than others. Brandts and Schram (2001) explore behavior in a setting whereby subjects report a contribution function that states contribution levels for various rates of transformation between the public and private accounts (returns to the public good) and shows substantially heterogeneity in motives. Whereas some subject behave in accordance with a utility function defined solely over own earnings, others behave in a manner consonant with some form of social-preference or other-regarding behavior. Kurzban and Houser (2001)use a circular public goods games whereby individuals were sequentially informed about aggregate contributions to the group and allowed to change their decision based on this information and classify individuals into three distinct types whose underlying motives for giving differ.

${ }^{10}$ Similarly, Krupka and Weber (2013) elicit beliefs about the social appropriateness of various allocation decisions in different variants of the dictator game and show similar heterogeneity in perceived norms for giving.
} 
In what follows we focus on a form of "green" preferences that accords well with the efficiency preference interpretation. Specifically, we preferences represented by the following utility structure:

$$
U_{i}\left(c_{i}, X \mid \Theta\right)=c_{i}+f_{i}(X)+s \Sigma_{j \neq i} f_{j}(X)
$$

Added to the standard neoclassical specification is an additional term, multiplied by a weight $s$, that includes the sum of other agents' valuation of the public good. ${ }^{11}$ This is a green preference in the sense that the agent desires the socially efficient outcome as in Charness and Rabin (2002). The preference structure implies that individual $i$ will adjust their own provision of the public good toward social efficiency. In our setting the $\alpha$ green agents with $\tilde{V}>1$ can be thought of as having utility as in (2). This is equivalent to setting $\tilde{V}=1+s(N-1)$ for these agents. The remaining $(1-\alpha)$ "non-green" agents will have strictly neoclassical utility (i.e., $s=0$ and $\tilde{V}=1$ ).

The standard first order conditions for the privately optimal provision of the public good are given in our model by:

$$
\left.h_{i}^{*}\right) \geq \tilde{V} f^{\prime}\left(x_{i}^{*}+X_{i \neq j}^{*}\right) \forall i
$$

with equality if $x_{i}>0$ and where $X_{i \neq j}^{*}$ is the sum of all agents $j \neq i$ privately supplied optimal levels of the public good. Combined with our assumption of common costs of provision, this allows a straightforward summary of the difference across agents:

\section{Lemma 1: Green agents provide more of the public good than non-green agents.}

The intuition behind Lemma 1 is straightforward. Since the marginal benefit associated with each unit of the public good is higher for green agents, they will always provide more of the public good than will non-green agents. Moreover, given our assumption of a common underlying cost structure, green agents will provide higher cost units of the public good

\footnotetext{
${ }^{11}$ In equation (2), the $i$ subscript is meant only to index agents as opposed to allow heterogeneity in utility over the public good.
} 
than non-greens. It is this wedge in the marginal cost of provision that underlies our results regarding optimal policy design. Figure 1 shows this graphically. Indexing green agents as $g$ and non-green agents as $u$, the privately optimal levels of provision are indicated by $\hat{x}_{g}$ and $\hat{x}_{u}$.

Next, we consider the cost minimizing allocation rules. Assuming increasing marginal costs (for example of energy conservation by individual households) the model immediately leads to the following:

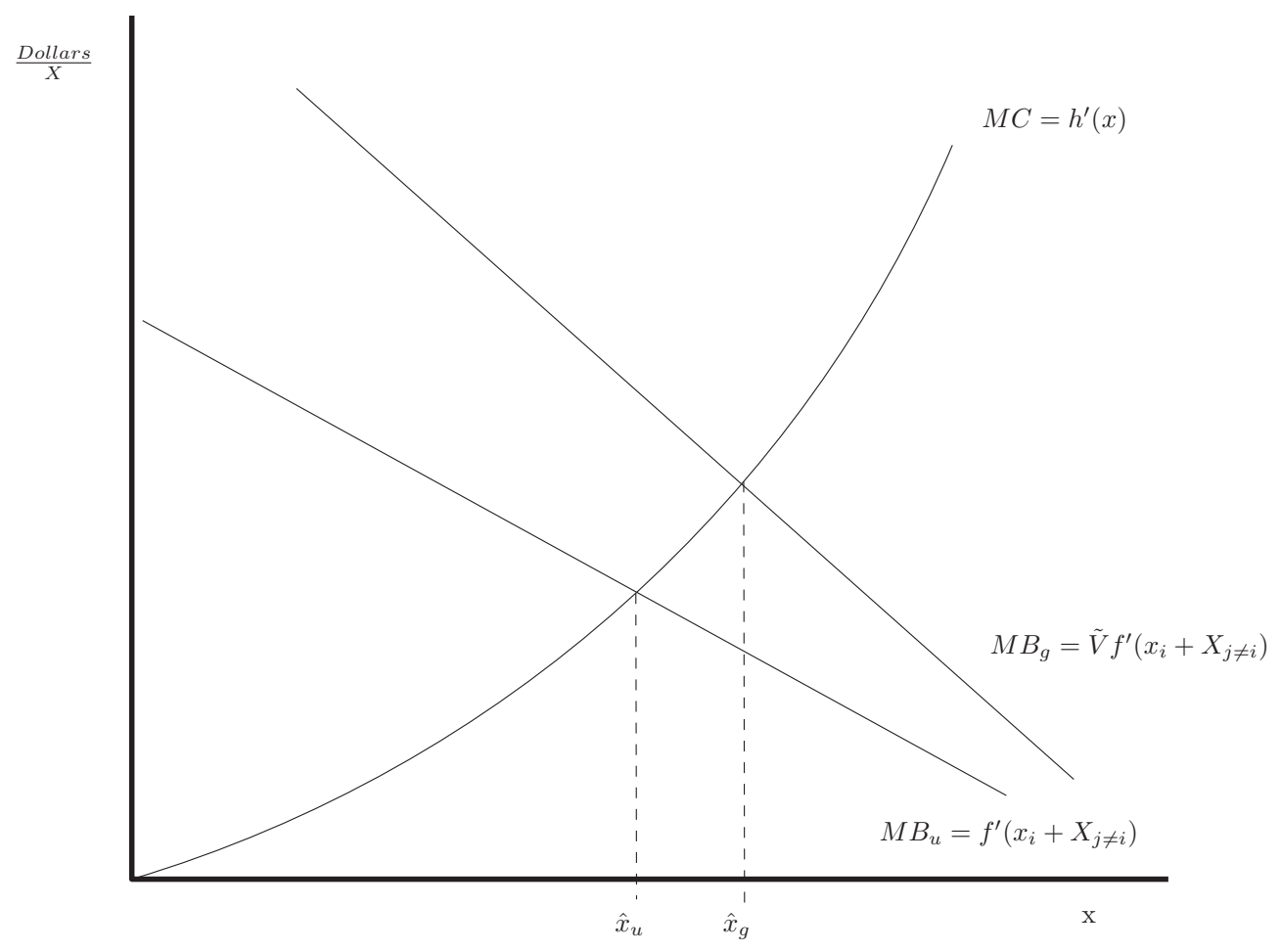

Figure 1: Basic Equilibrium

Proposition 1: For any level of public goods provision $\tilde{X}$, it is cost minimizing to have all agents provide identical quantities.

Corollary 1: With respect to direct effects, private provision of the public good is socially efficient if all agents have full social efficiency preferences. 
Proposition 1 is simply the classic equimarginal principle in the context of our model. Since the marginal cost of provision is increasing and symmetric across agents, the minimumcost provision of any aggregate $\tilde{X}$ will involve $x_{i}=x_{j}$. However, as noted in Figure 1 , the marginal cost of provision for green agents is larger than the marginal cost of provision for non-green agents. As a result, the private equilibrium cannot minimize cost. There is a wedge in marginal costs across agents. Hence, reallocating production of the last unit produced by a high-cost green agent to a lower cost non-green would lead to lower overall costs of provision.

Corollary 1 includes two important features that make it differ from the classic definition of equilibrium public goods provision (e.g. in Samuelson (1954)). First, each agent provides their own contribution of the public good through independent convex cost functions, $h(\cdot)$. These agents must therefore have the same preferences in order to guarantee provision of identical quantities as required for cost minimization. Second, these preferences must place enough weight on the public good to bring the aggregate level of provision up to the efficient level. The weights needed are given in (2) where $s=1$. Note that the social planner here implicitly only considers direct benefits of provision, contained in $f_{i}(X) .{ }^{12}$ We will abstract from the optimal level of public good provision in what follows by considering the planner's problem as a cost-minimization subject to reaching a specified level of provision in aggregate.

\subsection{Preference Heterogeneity and Policy Choice}

We now turn to the motivating question about cost-minimizing policy. We compare the performance of a price instrument (a subsidy for public good provision) to the performance of a standard that enforces a minimum level of public good provision. Before proceeding it is worth noting that, in our setting, a quota on emissions placed at the producer level will manifest as a price instrument from the perspective of consumers. For example, an emissions quota applying to electricity production will appear as higher electricity prices to

\footnotetext{
${ }^{12}$ If the planner also considers the feedbacks in the efficiency preference term (e.g., accounts for $s>0$ as opposed to only $\left.f_{i}(X)\right)$ it leads to a change in the optimal level of public good provision when the planner sums over utility functions.
} 
households - i.e., from the perspective of the end user it is akin to a price-based policy. For simplicity, we assume perfect enforcement of both policies and provide a third proposition.

Proposition 2: For any level of regulated public goods provision $\tilde{X}$ such that the standard binds for all agents, $\frac{\tilde{X}}{N} \geq \hat{x_{g}}$, a standard is always more efficient than a uniform price instrument.

Proposition 3: For any level of regulated public goods provision $\tilde{X}$ such that the standard binds for non-greens but not for green agents, $\hat{x}_{g} \geq \frac{\tilde{X}}{N} \geq \hat{x_{u}}$, a standard is always more efficient than a uniform price instrument.

The intuition behind Proposition 2 follows first from the equimarginal principle and our assumption of a common cost function. If the standard binds for all agents then they all provide $\frac{\tilde{X}}{N} \equiv \bar{x}$ units of the public good and reach aggregate provision at minimum cost. A uniform price subsidy, on the other hand, preserves a wedge in the level of provision between greens and non-greens. The difference in provision, and therefore marginal costs across types, means that the price policy will always be less efficient than a standard. Subsidies targeted by type can still produce efficiency though we will argue that these are infeasible in most situations and share an important similarity to standards in our context; they have greater impact on the decision of non-greens.

Although the mechanics are more complex, Proposition 3 results from the same violation of the equimarginal principle as Proposition 2: subsidies preserve a greater wedge in the marginal cost of provision across types. Since the standard in this case is not binding on green agents they will provide more of the public good under either policy. The key intuition for the result is that the subsidy increases provision from both types of agents while the standard only increases provision from non-green agents, who have relatively lower marginal costs of provision. The concavity of benefits from the public good introduces an indirect effect reinforcing this result: if, due to declining marginal benefits, the unconstrained green agents provide somewhat less of the good the wedge between the two types of agents will only be further reduced. The standard is therefore unambiguously preferred for any level 
of provision greater than the privately optimal level.

The effect of the price instruments and standards considered by Proposition 3 is shown graphically in Figures 2 and 3. In Figure 2, the subsidy for public good provision shifts the marginal benefit curve for both types up by the level of the subsidy, $\tau$. Each type sets private marginal benefit (now including the subsidy) equal to marginal cost, preserving a wedge in the marginal cost of provision across types: $M C\left(x_{u}(\tau)\right)<M C\left(x_{g}(\tau)\right)$. The size of the wedge is directly related to the inefficiency of the price instrument: on the margin it would be cheaper to have non-greens provide more of the good. As a result a price instrument cannot be efficient because the equimarginal principal is violated.

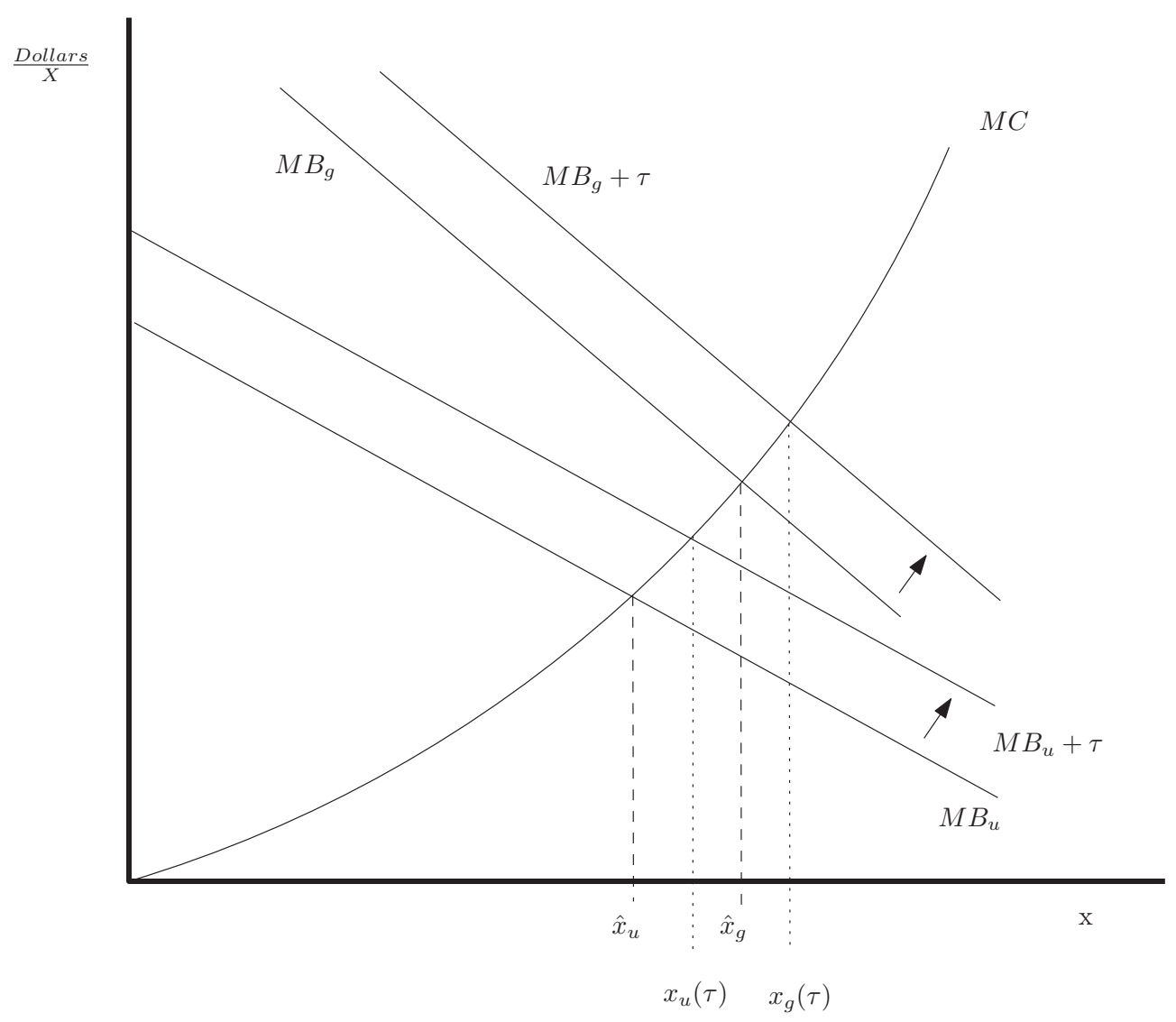

Figure 2: Equilibrium with a price instrument

Figure 3 shows the effect of a standard that binds only for the non-green type. In this case, the non-green agent must provide at a level greater than their private optimum 
$\left(\bar{x}>\hat{x}_{u}\right)$. This brings the marginal cost of provision for the two types closer together, holding the choice of the green agent fixed. As a result, the wedge in marginal costs across types is lower with a standard than with a price instrument. Since the wedge in marginal cost across types is lower, it is less costly to provide the same level of the public good.

In both Figure 2 and Figure 3 there are possible indirect effects of the policy instrument that also act to increase the relative efficiency of the standard. In both cases aggregate provision of the public good is rising which tends to lower the marginal benefit of additional private provision. In the case of the standard, non-green provision is fixed (at the level of the standard) so the indirect effect means greens will provide (weakly) less than before $\left(x_{g}(\tilde{X}) \leq \hat{x}_{g}\right)$. The direct and indirect effects of the standard then both act to narrow the wedge in marginal costs between non-green and green agents. Under a price instrument, in contrast, indirect effects will act on both greens and non-greens simultaneously and therefore preserve the costly wedge in provision.

In addition to demonstrating the advantage of a standard, the model also permits consideration of the relative size of this advantage with respect to two key parameters; the proportion of pro-social agents and the relative strength of their preferences. Corollaries 2 and 3 below are the first steps toward the comparison, and show how provision of each type of agent changes as a function of $\alpha$, the proportion of green agents, and $\tilde{V}$, the strength of their preferences under the price instrument:

Corollary 2: The provision of green agents in the case of price instruments, $x_{g}^{t}$, and the price instrument/subsidy needed to attain a given level of public good provision, $\tau$, are both always decreasing in the percentage of green agents, $\alpha$.

Corollary 3: The provision of green agents in the case of price instruments, $x_{g}^{t}$, is increasing and the price instrument/subsidy needed to attain a given level of public good provision, $\tau$, is decreasing in the strength of the green preference, $\tilde{V}$.

The intuition behind Corollary 2 is straightforward. The first part of the corollary follows directly from our assumption on convexity of $f(X)$; displacing one non-green agent with a green counterpart leads to an increase in aggregate production level. At prevailing provision levels, we thus have the marginal cost exceeds marginal benefit. In equilibrium, 


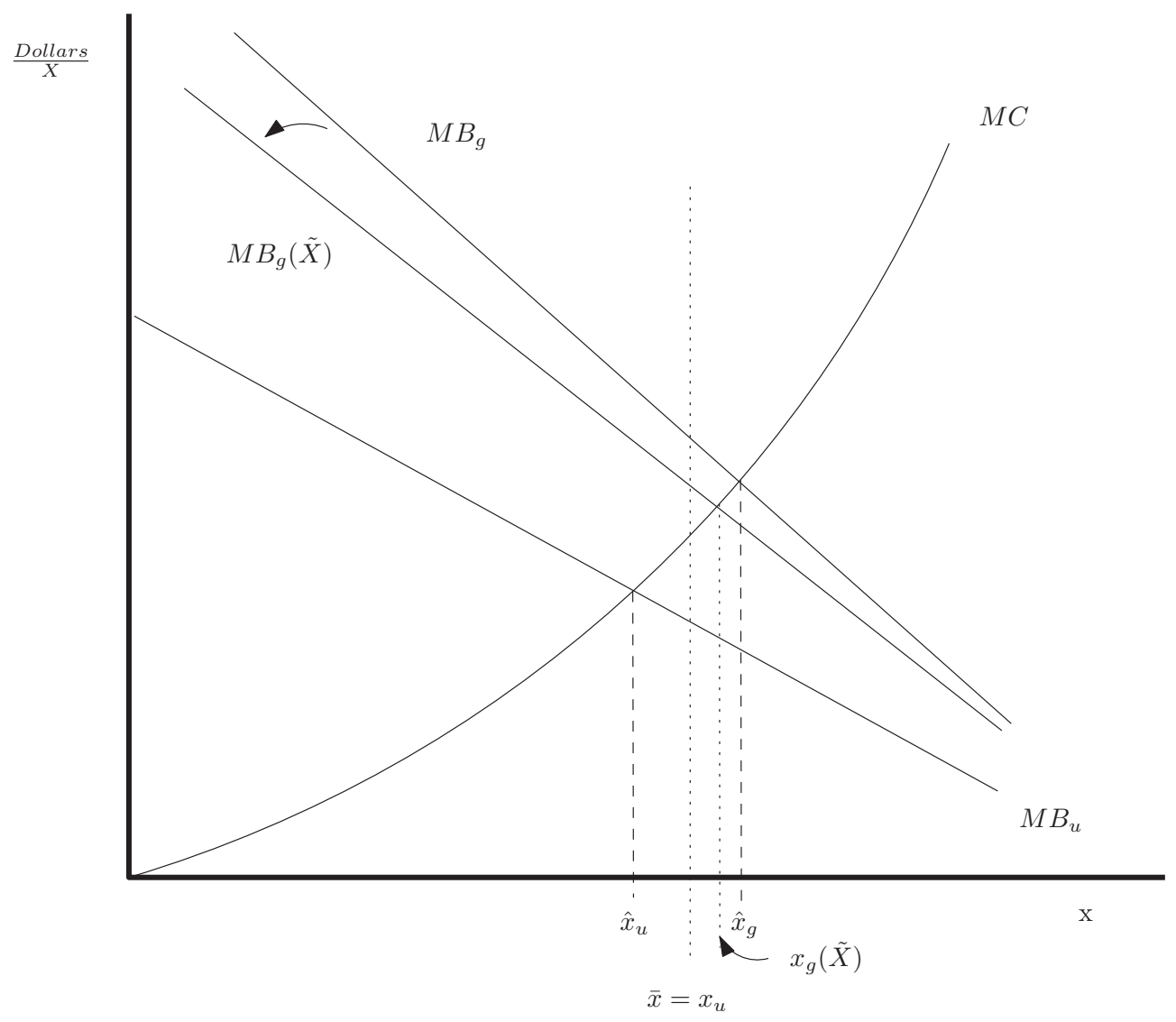

Figure 3: Equilibrium under a standard

we thus have that each agent will provide less of the public good.

The intuition for the second part of the corollary is as follows. The unregulated level of public good provision is directly related to the proportion of green agents in the economy. As the proportion of such agents increases, the change in provision required to achieve any target level of provision falls. By convexity of the marginal cost function, the resulting subsidy needed to achieve the desired change in provision falls. The intuition behind Corollary 3 is almost identical, except that now the increase in unregulated provision comes through increased strength of individual preferences in $\tilde{V}$ rather than an increase in the number of greens overall.

The corollaries lead to two results on the size of the cost advantage offered by a standard: 
Proposition 4: For any level of regulated public goods provision, $\tilde{X}$, such that the standard binds on all agents, $\frac{\tilde{X}}{N} \geq \hat{x}_{g}$, the difference in welfare between the two policies, $\Delta_{t s}$, is single peaked in the percentage of green agents, $\alpha$.

The intuition underlying Proposition 4 is again straightforward. Consider first the case where all agents are of a given type. In this case, the two policies are equivalent and there is no difference in welfare. However, the welfare effects of the two policies begin to diverge once we allow for heterogeneity in preferences. In such a world, agents provide different levels of the public good at different marginal costs under the price instrument but face identical costs under a binding standard.

Corollary 4: For any level of regulated public goods provision $\tilde{X}$ such that the standard binds for all agents, $\frac{\tilde{X}}{N} \geq \hat{x_{g}}$, the difference in welfare between the two policies, $\Delta_{t s}$, is everywhere increasing in the strength of the green preference, $\tilde{V}$.

The intuition for Corollary 4 is as follows. By convexity of the cost function, the welfare gain that arise when reallocating one unit of provision from a green to a non-green agent is greater the greater the initial wedge in costs. As shown above, stronger green preference, $\tilde{V}$, induces more provision from green agents and increases the wedge between green and nongreen provision. As a result, the tax leads to progressively greater costs than the standard as the strength of the green preference increases.

Taken together, the results in this subsection consider the effect on public goods provision when a fraction of people in the economy have pro-social preferences. We show how such types provide more of the public good in an unregulated setting, leading to a wedge in the marginal cost of provision between greens and others in the economy. This wedge is preserved if the government employs a uniform price instrument to promote increased provision of the public good. Standards, in contrast, have a greater impact on non-greens and thus serve to reduce the cost wedge and lower the costs of obtaining any given level of provision. Finally, we find the relative benefit of standards over price instruments is increasing in the degree of preference heterogeneity in the economy. In our model, this comes through two channels - stronger preferences among individual greens or an increase 
in their overall number.

\subsection{Asymmetric Instruments and Costs}

We now relax the assumptions of the model along two key dimensions. First, we consider the possibility of an asymmetric policy instrument where greens can receive a different subsidy than non-greens. Second, we consider asymmetry in the costs of provision, allowing greens to have larger or smaller costs of providing the public good than non-greens.

Proposition 5: There is an asymmetric price instrument which leads to efficient provision of any level of the public good, $\tilde{X}$. Under such a policy, the subsidy for non-greens, $\tau_{u}$, is strictly larger than the subsidy for greens, $\tau_{g}$.

The intuition for Proposition 5 is related to the classic Lindahl price solution in public goods problems. The difference here comes from our assumption of convex costs, which necessitates equal provision of the goods across types for efficiency. An asymmetric price policy can achieve this. Under any such policy, the social planner uses targeted subsidies to shift each agent's marginal benefit curve such that it intersects the marginal cost curve at the same point. The resulting equilibrium would entail each agent providing the same level of the public good at the same cost thereby making the provision efficient.

However, this policy would be quite difficult to implement in most settings due to the difficulty in accurately identifying each type. More problematic, however, is the potential for resale of products purchased by non-greens to greens. Since non-greens receive a greater subsidy than greens, they could profitably resell products to greens at a lower prices than what such types would face in the market. Such resale trade could lead to inefficient levels of public good provision. Intuitively, the problems in implementing such a scheme are akin to those faced by a third-degree price discriminator under resale.

We next consider asymmetries across types in the cost of providing the good. To varying degrees, such asymmetries are quite likely to exist across many important policy settings. ${ }^{13}$

\footnotetext{
${ }^{13}$ In the context of our model, warm-glow or any preference that is defined over the individual's contribution level is qualitatively similar to cost heterogeneity. Such preferences lower the "cost" to the agent of providing any aggregate level of the public good.
} 
To explore cost asymmetries we assume that green agents, in addition to having the $\tilde{V}$ parameter governing the strength of their green preferences, green agent also have a parameter $\delta$ differentiating their marginal costs of abatement. The green agent's maximization problem thus becomes:

$$
\begin{array}{rr}
U_{g}\left(c_{g}, X \mid \Theta\right)= & c_{g}+\tilde{V} f(X) \\
& \text { s.t. } y_{g}=c_{g}+\delta h\left(x_{g}\right) \\
\Rightarrow U_{g}\left(c_{g}, X \mid \Theta\right)= & y_{g}-\delta h\left(x_{g}\right)+\tilde{V} f(X)
\end{array}
$$

where values of $\delta$ greater than 1 scale up the cost of abatement for greens (making cost positively correlated with pro-social preferences), and values less than 1 scale it down (introducing a negative correlation). This extension leads to the following two propositions:

Proposition 6: With asymmetric costs, the amount of public good provided by greens is inversely related to their relative cost position. The (uniform) subsidy needed to reach any level of public goods provision is increasing in the relative marginal cost of provision for green agents.

Proposition 6 states two very intuitive results. First, as the cost of provision for green agents increases they provide less of the public good. Second, holding the cost of provision for non-greens constant, the subsidy required to induce any given level of public good provision is increasing in the cost of provision for green.

Proposition 7: With asymmetric costs, the relative efficiency of a uniform price instrument vis-a-vis a standard is greater when the costs for green agents are negatively correlated with the strength of their green preferences. subject to one regularity condition

Proposition 7 states that the relative benefits of standards over price instruments falls if green agents have a lower cost of provision than non-green agents. Conversely, the relative benefits of standards over taxes can rise if green agents have a higher cost of provision and the standard only binds for non-green types. The intuition for these results is shown in Figure 4 below. The figure provides an example where provision in the unregulated 
equilibrium is in fact efficient as the green agent's marginal cost of abatement curve is sufficiently less than the non-green agent's costs. In this example, it is easy to see how a uniform subsidy can maintain efficiency by shifting both types' provision up. A standard, in contrast, will introduce a wedge in marginal costs leading to a reduction in social welfare.

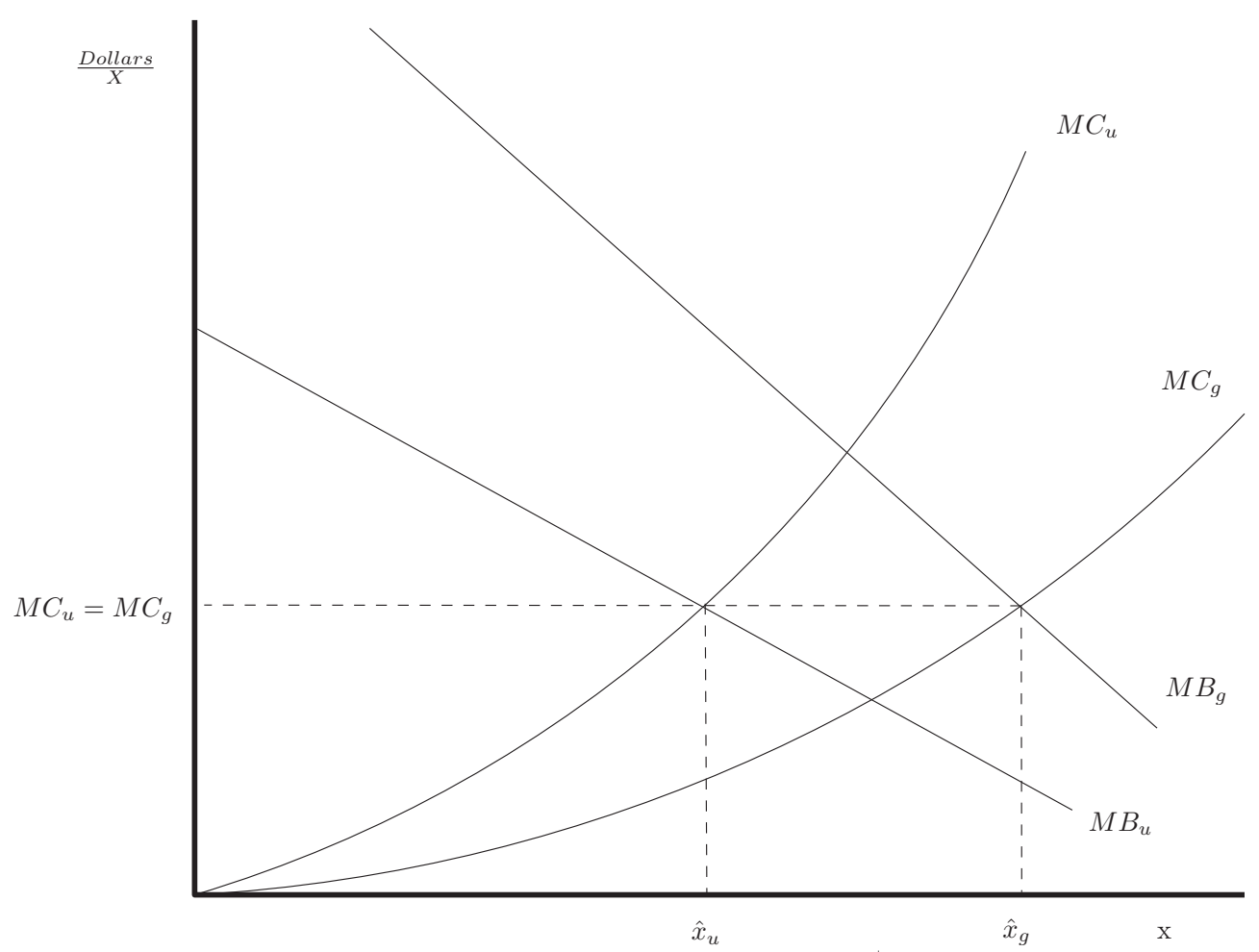

Figure 4: Case of Asymmetric Costs of Abatement

More broadly, the propositions here suggest that cost heterogeneity will tend to decrease the advantage of a standard relative to a subsidy. Generally, if the magnitude of the cost heterogeneity is sufficiently large, the subsidy policy will dominate the standard. The extreme case makes the intuition clear: consider the situation where benefit heterogeneity is infinitesimally small and cost heterogeneity is large. The model then reduces to a classical public goods problem with heterogeneous costs in which the price instrument dominates. Below, we provide a more precise depiction of these competing effects and how they impact the relative superiority of standards using a simple quadratic approximation. 


\section{A Simple Quadratic Example}

The key inequalities can be derived from the general model above but there is also important intuition in a parsimonious analytical example: Below we assume a simple quadratic approximation and solve explicitly for the advantage of a standard relative to a price-based instrument. We then investigate how each factor contributes to the degree of the standard's advantage. The example makes explicit the competing effects from heterogeneity in cost and heterogeneity in green preferences and how they impact the choice of policy instrument.

We assume here that the marginal benefit from provision of the public good is constant and that the marginal cost of provision rises linearly from the origin. Although this imposes a particularly strong structure, we believe that such a parameterization fits well with a number of policy relevant scenarios. For example, reductions in carbon emissions in a particular country and year, are likely to fit the constant marginal benefits case closely. ${ }^{14}$ Linearly increasing marginal cost - of energy conservation to stay with the climate example keeps the parameterization simple but also fits a number of technologies, such as automobile fuel economy, quite well.

Our example then defines:

$$
\begin{aligned}
& f_{i}^{\prime}(X)=m(\text { constant marginal benefits }) \\
& h^{\prime}\left(x_{i}\right)=b x_{i}(\text { marginal cost rises linearly at rate } b)
\end{aligned}
$$

Deriving the solution to the utility maximization problem given in (1) under a tax $\tau$ or standard $\bar{x}$ is straightforward. We consider policies that achieve a fixed total provision of $\tilde{X}$ and bind on all agents - i.e., we set $\tilde{X}$ such that $\left(\bar{x} \geq \hat{x_{g}}\right.$, as in Proposition 3$)$. Defining $\Delta_{t s}$ as the cost advantage that a standard has over a price-based policy we obtain the following simple expression:

$$
\Delta_{t s}=\alpha(1-\alpha) \frac{m^{2}(\tilde{V}-1)^{2}}{b}
$$

\footnotetext{
${ }^{14}$ The intuition is that a year's change in one country will affect global climate only slightly, while any nonlinearity in benefits is likely to appear only for much larger temperature movements.
} 
First notice that the advantage of the standard is increasing in both the square of $m$ and $\tilde{V}$. The greater the strength of pro-social preferences among greens $(\tilde{V})$ or the marginal benefits from the public good $(m)$ the bigger is the initial wedge in conservation choice between greens and non-greens. The standard overcomes this difference, achieving the first best, whereas the price-based policy maintains this wedge and is thus a more costly way to attain $\tilde{X}$.

Next we observe that as $b$ declines and marginal costs become flatter, the advantage of the standard increases even further. This is at first counterintuitive, but notice that the levels of $\tilde{V}$ and $m$ alone determine the absolute difference in marginal costs between greens and non-greens. Holding the difference in marginal costs fixed, small values of $b$ imply large differences in absolute levels of private provision. ${ }^{15}$

We next consider how the share of greens, $\alpha$, impacts the relative advantage of a standard. If everyone is green or everyone is non-green ( $\alpha=1$ or 0 ) our model reduces to the standard equivalence between the two policies. Proposition 5 shows that the advantage of the standard has a single peak in $\alpha$. In this example the peak occurs at $\alpha=1 / 2$. Intuitively this is where the degree of heterogeneity in the population is maximized and the benefit of reallocating provision from green to non-green agents the greatest.

We finally explore the case where heterogeneity exists both in green preferences and in marginal costs of provision. The effects of cost heterogeneity on optimal policy choice is quite intuitive in this setting. Allowing marginal costs to differ, $h^{\prime}\left(x_{g}\right)=b_{g} x_{g}$ and $h^{\prime}\left(x_{u}\right)=b_{u} x_{u}$, and solving as before yields:

$$
\Delta_{t s}>0 \Leftrightarrow m(\tilde{V}-1)>\left|b_{g}-b_{u}\right| \tilde{X}
$$

That is, the standard is preferred as long as the wedge between the green and nongreen's benefits is greater than the absolute difference in their marginal costs of provision. When preference heterogeneity is relatively large, the standard dominates. When cost heterogeneity is relatively large, the price-based policy dominates.

\footnotetext{
${ }^{15}$ We cannot examine the case as $b$ goes to 0 in this parameterization since the green's private provision, $\hat{x_{g}}$, tends to infinity, removing the need for policy.
} 


\section{Policy Applications}

Our model applies in any setting where provision of public goods is left to individuals facing convex costs. ${ }^{16}$ However, we focus our discussion on a particular application that we believe accords well with our basic set-up; household energy conservation. Within this realm, each additional step toward zero energy use for the household comes with increasing cost. Further, we restrict our discussion to examples where cost side heterogeneity is likely small; that is we focus on examples where preference heterogeneity is likely to exert a relatively large influence on policy choice.

\subsection{Lighting Technology Choice}

Consider the ability of a household to provide a public good (energy conservation) through the purchase of more efficient lightbulbs. Each household works its way out a common marginal cost curve by selecting one of a variety of ever more expensive bulbs: standard incandescents, halogen incandescents, compact fluorescents, and LED-based bulbs. ${ }^{17}$ Moreover, consumers differ widely in their initial desire to conserve, with the resulting purchases spread across the spectrum of bulb choices.

U.S. state and federal governments are currently intervening to increase light bulb efficiency. The policies act on one margin of choice, bulb selection at the store, and the two types of policies currently in place line up directly with the two alternatives in our model. "Price-based" policies are simply subsidies to more efficient bulbs and are historically the predominant way to stimulate the purchase of energy efficient lighting. The alternative, minimum standard policies, have been introduced more recently. For example, California's AB 1109 places a minimum standard that phases out standard incandescents between 2011 and 2013. Under this legislation, halogen incandescents become the minimum-efficiency

\footnotetext{
${ }^{16}$ The individual nature of the costs is a key component of our setting: if the public good is produced centrally (consider highway construction) the cost penalty associated with different contributions by greens and non-greens is removed.

${ }^{17}$ By assuming a common marginal cost curve we assume that consumers place equal value on other differences in the bulbs (for example quality of light or sound emissions). Heterogeneity in preferences for these aspects introduces cost-heterogeneity in the language of our model, then competing with the degree of green preference heterogeneity in determining optimal policy.
} 
bulb permitted by the standard. A federal minimum-standard, roughly one year behind the California law in timing, has similar provisions. Yet the federal law has proven contentious to the point that congress acted to suspend enforcement in late $2011 .{ }^{18}$

Under the assumptions of our model the more recent minimum standards on lightbulbs will provide the least-cost option for promoting the adoption of energy efficient lighting. The existing broad subsidies to efficient bulbs move everyone's choice farther out the technology cost curve, preserving the gap between greens and non-greens. The minimum standards instead push all consumers only as far as the halogen bulbs, taking advantage of a lowcost conservation option available to non-greens without distorting the incentives faced by greens. Note that there will still be heterogeneity as the greens purchasing CFL's or LED bulbs will presumably continue to do so. However, the advantage of the minimum standard is that it brings us closer to the equimarginal case. This corresponds to the situation considered in Proposition 4, where the standard binds only on the non-green consumers.

More generally, the light bulb example can be extended to electricity usage. Insofar as decreased electricity usage provides a public good through cleaner air and lower greenhouse gases from reduced fossil fuel consumption, federal and state governments pay significant attention to accomplishing this at the lowest possible social cost. Households choose an entire suite of energy using durables (for example refrigerators, air conditioners, and windows) each of which can be selected from a range of efficiencies.

While a tax on electricity would decrease electricity usage as long as households face the same prices for durable goods (e.g., increasing identical marginal costs) our model implies taxing electricity would be more costly than a standard. A standard in this example takes the form of subsidizing or taxing a particular durable good. For example, a large tax on very inefficient refrigerators effectively bans them. Similarly, a subsidy to very efficient durable goods products flattens the marginal cost curve of all agents in the economy. Such subsidies are commonly offered by local utilities for individuals that install energy efficient appliances to replace old inefficient ones (Alberini, Gans, and Towe (2013)).

\footnotetext{
${ }^{18}$ See "Let There Be Light Bulbs" in the Wall Street Journal (July 15th, 2011) and the more recent suspension of the law "Congress Kills Light Bulb Ban - Sort Of" in Forbes (December 16, 2011).
} 
An important caveat here is that our model considers only one margin of choice. We can compare the two competing policy interventions for light bulbs because they act on exactly the same margin of choice. However, we cannot draw comparisons with other policies in the portfolio such as an advertising campaign or normative messages that promote turning off lights when leaving a room or similar behavioral adjustments (e.g., Costa and Kahn (2011), Allcott (2011), Ferraro and Price (2013), Ito, Ida, and Tanaka (2013), or Metcalfe and Dolan (2013)).

\subsection{Automobile Choice}

The automobile choice decision again fits within the basic scope of our model. In order to provide ever more conservation through vehicle choice a household faces a convexly increasing purchase price. To provide a sense for this Figure 5 displays a set of engineering features than can improve fuel economy in a typical compact car. The data points are from National Research Council (2002) and hold all vehicle characteristics other than fuel economy fixed. Marginal costs increase roughly linearly. Heterogeneity among existing consumers means that some vehicles presently include these low-cost improvements whereas others do not. Households with even stronger preferences for conservation buy cars that include every one of these improvements and may go well beyond, adding hybrid or even electric drivetrains. At the same time many non-greens fail to provide even a minimal level of conservation when making their car purchase decisions.

The existing literature on gasoline use tends to focus on multiple margins of choice: the car purchase decision is interacted with the choice over how many miles to drive (see, e.g., Parry, Walls, and Harrington (2007)). While both margins are certainly important, we restrict ourselves here to policies that act solely on vehicle choice. ${ }^{19}$ This margin is the key focus of current gasoline conservation efforts in the U.S., for example the near-doubling of fuel economy standards by 2020 (see The White House Office of the Press Secretary (2011)).

\footnotetext{
${ }^{19}$ While we would be the first to argue that controlling miles driven is also important to reduce gasoline use, accidents, and congestion, this margin of choice has been pursued much less intensively.
} 


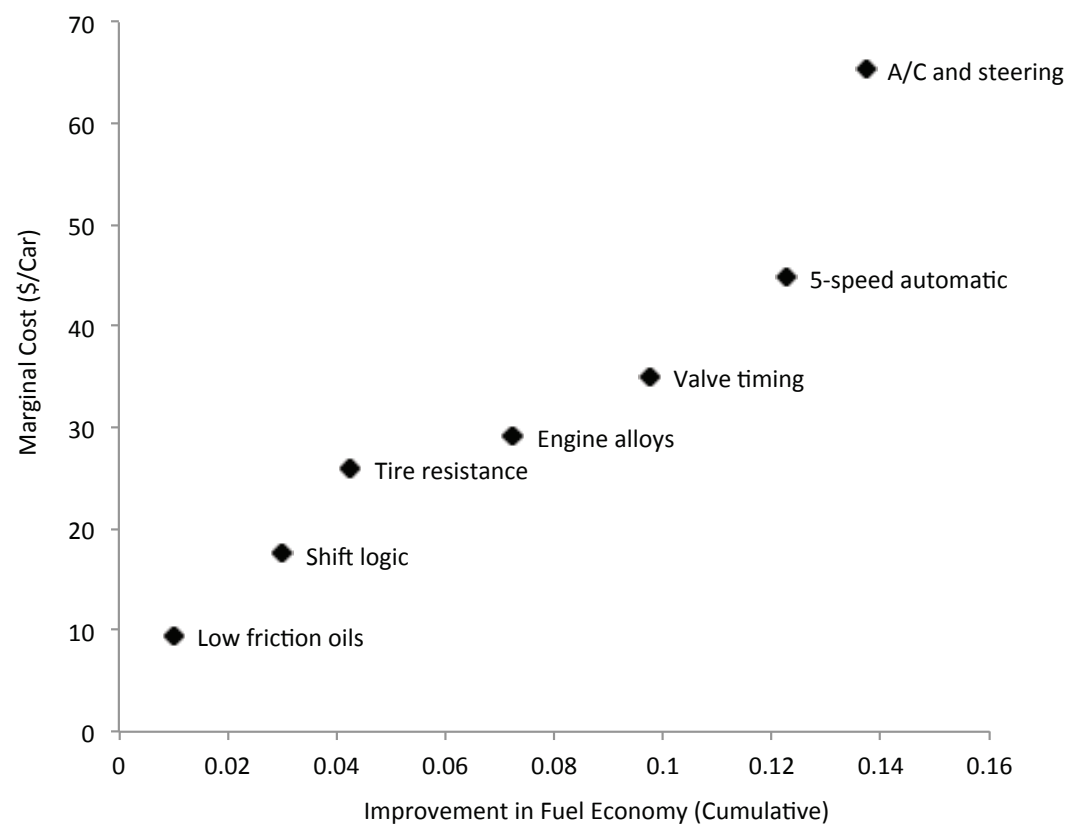

Figure 5: Engineering Cost of Improved Fuel Economy (Typical Compact)

Specifically, the U.S. effort to influence automobile choice has been dominated by the Corporate Average Fuel Economy (CAFE) standards - policies which restrict the average efficiency of all vehicles a manufacturer sells. In the context of our model, CAFE is a price-based policy since it places a shadow tax on inefficient vehicles that bring down a manufacturer's average and a shadow subsidy on the efficient cars. In this sense, CAFE suffers from exactly the cost inefficiency we identify in our theoretical model: it pushes both greens and non-greens toward more fuel-efficient vehicles, sending them farther out their individual cost curves for conservation. CAFE fails to take advantage of the fact that the cheapest conservation options on the margin are currently only available to the non-greens since these improvements have already been adopted in most vehicles that greens would consider.

In this setting our model again finds that a minimum standard on vehicle efficiency (or 
efficiency relative to weight, size, or horsepower) would have lower costs. ${ }^{20}$ In the U.S., the closest existing policy to a minimum standard for vehicles might be the gas guzzler tax. The guzzler tax looks like a minimum standard here since it applies only to a subset of the least efficient vehicles - those with fuel economy under $22.5 \mathrm{mpg} .{ }^{21}$ It therefore acts to bring up the fuel efficiency choices of the non-greens, to the extent they currently locate under $22.5 \mathrm{mpg}$, without interfering in the choices made by greens who locate above the cutoff. Interestingly, the guzzler tax' lack of influence on choices above $22.5 \mathrm{mpg}$ is sometimes pointed to as a failing. Yet our model suggests that this aspect is exactly what makes it more efficient. The least green consumers tend to be the ones that still have the cheapest options for conservation remaining, providing an efficiency advantage to policy that influences their decisions without distorting the choices of those already face high costs of provision.

\section{Conclusion}

We model an economy populated by two types of agents that differ with respect to their preferences for a public good. Whereas some agents care only about their own returns from the public good, others have "green" preferences and care about the benefits received by both themselves and others in the economy. Since both types of agents face identical, but convex, costs of provision, the private equilibrium involves greens working up their marginal cost curve and providing units of the public good that are more costly on the margin than provision by non-greens.

We use this basic framework to compare the relative performance of different policies designed to promote increased private provision. We find that minimum standards, like those on lightbulb efficiency or a gas-guzzler tax, can provide an increase in aggregate provision of the public good at lower cost than price-based incentives. Standards tend to reduce the heterogeneity in individual provision and therefore reduce total cost. Price-

\footnotetext{
${ }^{20}$ Such a standard would be akin to the lightbulb standard which is placed on energy use per lumen.

${ }^{21}$ Consider the extreme case for clarity: a very high guzzler tax would essentially eliminate vehicles under $22.5 \mathrm{mpg}$ without distorting decisions on vehicles above that cutoff, in essence a minimum standard.
} 
based policies, on the other hand, place the same incentive on all individuals and so preserve inefficiency stemming from uneven provision of the public good. It is important to note that this result relies on the source of heterogeneity assumed in the model - differences in the marginal benefit of public good provision.

Preferences are of course not the only dimension along which heterogeneity is likely to appear. In many applied settings, agents will also face heterogeneous costs of provision. To capture this possibility, we extended the basic model to allow both sources together. When cost heterogeneity is relatively large in magnitude a price-based policy dominates. However, the opposite holds when heterogeneity in pro-social preferences is the more important component. We argue that many important policy questions, for example the case of lightbulbs or some low-cost technologies in cars, are likely to present relatively homogeneous costs and therefore fit the assumptions of our main model quite closely. Other settings are likely to exhibit substantial differences both in green preferences and the costs of provision. Consider for example the conservation of energy through reduced use of air conditioning. Some individuals may have very strong green motivation for higher thermostat settings and thus exhibit the type of preference heterogeneity considered in our model. At the same time considerable variation is also likely in the utility people give up due to warmer indoor temperature - the cost side in our model. Our results suggest that optimal policy choice in such a setting depends pivotally on the degree of heterogeneity along these two dimensions.

In closing, we should note that our model and the results herein suggest a number of important extensions. We focus on a single margin, for example a policy designed to influence the purchase decision of an energy-using appliance. Other margins such as the utilization of energy consuming durables or vehicle miles traveled will be important in many applications. $^{22}$ In such settings, one would need to consider a broader set of policies than those considered here. Further, we employ a model with only two types while a continuum of preferences might better reflect empirical differences in the provision of public goods. This could provide further generalization of our key results. Finally, we should note that our

\footnotetext{
${ }^{22}$ Hausman (1979) and a rich subsequent literature consider interactions between purchase and utilization of durables, for example.
} 
model raises an interesting dilemma concerning incidence. The cost-minimizing standard places greater burden on those who value the public good least: non-greens. An interesting direction for future work is thus to explore the distributional impacts of various policy options and how the costs of providing a given level of the public good would change with the imposition of a compensation requirement as in Bovenberg, Goulder, and Jacobsen (2008). Careful analysis of the incidence dilemma would contribute to the larger political economy question of how the exact form of heterogeneity in preferences for the public good, and policy designed with them in mind, affects optimal public good levels. 


\section{References}

Akerlof, G. A., and R. E. Kranton (2000): "Economics and Identity," Quarterly Journal of Economics, 155(3), 373-399.

Alberini, A., W. Gans, and C. Towe (2013): "Energy Efficiency Incentives: Do They Work for Heating and Cooling Equipment? Evidence from Maryland Homeowners," University of Maryland Working Paper.

Allcott, H. (2011): "Social Norms and Energy Conservation," Journal of Public Economics, 95(9), 1082-1095.

Allcott, H., S. Mullainathan, and D. Taubinksy (2012): "Externalities, Internalities and the Targeting of Energy Policy," NYU Working Paper.

Andreoni, J. (1989): "Giving with Impure Altruism: Applications to Charity and Ricardian Equivalence," Journal of Political Economy, 97(6), 1447-1458.

Andreoni, J. (1990): "Impure Altruism and Donations to Public Goods: A Theory of Warm-Glow Giving," The Economic Journal, 97(6), 1447-1458.

Becker, G. (1974): "A Theory of Social Interactions," Journal of Political Economy, 82(6), 1063-1093.

Benabou, R., And J. Tirole (2006): "Incentives and Prosocial Behavior," American Economic Review, 96(5), 1652-1678.

BovenberG, L., L. Goulder, and M. Jacobsen (2008): "Costs of Alternative Environmental Policy Instruments in the Presence of Industry Compensation Requirements," Journal of Public Economics, 92(5), 1236-1253.

Brandts, J., And A. Schram (2001): "Cooperation and Noise in Public Goods Experiments: Applying the Contribution Function Approach," Journal of Public Economics, $79(2), 399-427$. 
Charness, G., and M. Rabin (2002): "Understanding Social Preferences with Simple Tests," The Quarterly Journal of Economics, 117(3), 817-869.

Costa, D., And M. Kahn (2011): "Energy Conservation Nudges and Environmentalist Ideology: Evidence from a Randomized Residential Electricity Field Experiment," NBER Working Paper 15939.

Della Vigna, S., J. List, and U. Malmendier (2012): "Testing for Altruism and Social Pressure in Charitable Giving," Quarterly Journal of Economics, 127(1), 1-56.

Ferraro, P., and M. Price (2013): "Using Non-Pecuniary Strategies to Influence Behavior: Evidence from a Large Scale Field Expirement," Review of Economics and Statistics, Forthcoming.

Fischbacher, U., And S. Gaechter (2008): "Heterogeneous Social Preferences and the Dynamics of Free Riding in Public Goods Experiments," TWI Research Paper Series, 27.

Glazer, A., And K. Konrad (1996): "A Signaling Explanation for Charity," American Economic Review, 86(4), 1019-1028.

Hausman, J. (1979): "Individual Discount Rates and the Purchase and Utilization of Energy-Usage Durables," Bell Journal of Economics, 10(1), 387-389.

Hoel, M., And L. KARP (2001): "Taxes and quotas for a stock pollutant with Multiplicative Uncertainty," Journal of Public Economics, 82, 91-114.

Holland, S. (2012): "Taxes and Trading versus Intensity Standards: Second-Best Environmental Policies with Incomplete Regulation (Leakage) or Market Power," Journal of Environmental Economics and Management, 63(3), 375-387.

Holland, S., J. Hughes, and C. Knittel (2009): "Greenhouse Gas Reductions under Low Carbon Fuel Standards?," American Economic Journal: Economic Policy, 1(1), $106-146$. 
Hollander, H. (1990): “A Social Exchange Approach to Voluntary Cooperation," American Economic Review, 80(5), 1157-1167.

Ito, K., T. IdA, And M. Tanaka (2013): "Using Dynamic Electricity Pricing to Address Energy Crises Evidence from Randomized Field Experiments," Boston University Working Paper.

Jacobsen, M. (2013): "Evaluating US Fuel Economy Standards in a Model with Producer and Household Heterogeneity," American Economic Journal: Economic Policy, forthcoming.

Kotchen, M., and M. Moore (2007): "Private Provision of Environmental Public Goods: Household Participation in Green Electricity Programs," Journal of Environmental Economics and Management, 53, 1-16.

Krupka, E., and R. Weber (2013): "Identifying Social Norms Using Coordination Games: Why Does Dictator Game Sharing Vary?," Journal of the European Economic Association, 11(3), 495-524.

Kurzban, R., And D. Houser (2001): "Individual Differences in Cooperation in a Circular Public Goods Game," European Journal of Personality, 1(3), S37- S52.

Levine, D. (1998): "Modeling Altruism and Spitefulness in Experiments," Review of Economic Dynamics, 1(3), 593-622.

Metcalfe, R., and P. Dolan (2013): "Neighbors, Knowledge, and Nuggets: Two Natural Field Experiments on the Role of Incentives on Energy Conservation," University of Chicago Working Paper.

National Research Council (2002): Effectiveness and Impact of Corporate Average Fuel Economy (CAFE) Standards. Washington, DC: National Academy of Sciences.

Parry, I., M. Walls, and W. Harrington (2007): "Automobile Externalities and Policies," Journal of Economic Literature, 45, 373-399. 
Poortinga, W., L. Steg, C. Vlek, and G. Wiersma (2003): "Environmental constraints on hydropower: An ex post benefit-cost analysis of dam relicensing in Michigan," Journal of Economic Psychology, 24(1), 49-64.

Samuelson, P. (1954): "The Pure Theory of Public Expenditure," Review of Economics and Statistics, 36, 387-389.

Saphores, J., H. Nixon, O. Gounseitan, and A. Shapiro (2007): "California Households' Willingness to Pay for "Green" Electronics," Journal of Environmental Planning and Management, 50(1), 113-133.

Segerson, K. (1988): "Uncertainty and Incentives for Nonpoint Pollution Control," Journal of Environmental Economics and Management, 15(1), 87 - 98.

The White House Office of the Press Secretary (2011): "President Obama Announces Historic 54.5 MPG Fuel Efficiency Standard," (July 29, 2011).

Weitzman, M. (1974): "Prices Versus Quantities," Review of Economics Studies, 41, $477-491$. 


\section{Appendix A}

Lemma 1: Green agents always provide more of the public good than non-green agents.

PROOF: By definition, $\tilde{V}$ is strictly larger for greens than non-greens. Private equilibrium provision for greens, $\hat{x_{g}}$, and non-greens, $\hat{x_{u}}$, are implicitly defined by the following system of equations:

$$
\begin{array}{r}
h^{\prime}\left(\hat{x_{g}}\right)=\tilde{V} f^{\prime}\left(\alpha N \hat{x_{g}}+(1-\alpha) N \hat{x_{u}}\right) \\
h^{\prime}\left(\hat{x_{u}}\right)=f^{\prime}\left(\alpha N \hat{x_{g}}+(1-\alpha) N \hat{x_{u}}\right)
\end{array}
$$

Since $\tilde{V}>1$ it must be that $\hat{x_{g}}>\hat{x_{u}}$ giving the desired result.

Proposition 1: For any level of public goods provision $\tilde{X}$, it is cost minimizing to have all agents provide identical quantities.

PROOF: Set up the cost minimization problem directly with a lagrangian such that

$$
\begin{array}{ll}
\min _{\underline{x}} & \Sigma_{i} h\left(x_{i}\right) \\
\text { s.t. } & \Sigma_{i} x_{i}=\tilde{X} \\
\rightarrow & L=\Sigma_{i} h\left(x_{i}\right)+\lambda\left[\tilde{X}-\Sigma_{i} x_{i}\right]
\end{array}
$$

The first order conditions for this lagrangian are $h^{\prime}\left(x_{i}\right)=\lambda \forall i=1,2, \ldots, N$ implying that $h^{\prime}\left(x_{i}\right)=h^{\prime}\left(x_{j}\right) \forall i, j$ which gives the desired result.

Corollary 1: With respect to direct effects, private provision of the public good is socially efficient if all agents have full social efficiency preferences. 
PROOF: Economy wide social efficiency preferences are defined by parameters $\alpha=1$ and $s=1 \rightarrow \tilde{V}=N$. In this case, the privately provided equilibrium is defined by the single equation $h^{\prime}\left(\hat{x_{g}}\right)=N f^{\prime}\left(N \hat{x_{g}}\right)$. Accounting only for the direct benefits accruing to agents (e.g., not the social efficiency component of their preference), the socially optimal level of the public good satisfies the following condition

$$
\Sigma_{i} h^{\prime}\left(x_{i}^{*}\right)=N f^{\prime}\left(N x_{i}^{*}\right)
$$

Equation (12) states that the sum of the marginal costs for each agent's provision must equal the sum of the marginal benefits. Summing up the direct effect of all agents' private provision gives: $\Sigma h^{\prime}\left(\hat{x_{g}}\right)=N f^{\prime}\left(N \hat{x_{g}}\right)$. By strict concavity of $h(\cdot), x_{g}=x_{i}^{*}$ giving the desired result.

Proposition 2: For any level of regulated public goods provision $\tilde{X}$ such that the standard binds for all agents, $\frac{\tilde{X}}{N} \geq \hat{x_{g}}$, a standard is always more efficient than a uniform price instrument.

PROOF: Choose a price instrument, $\tau$ such that $\Sigma_{i} x_{i}=\tilde{X}$. The price instrument, $\tau$, enters the budget constraint as $y=c+h\left(x_{i}\right)-\tau x_{i}$. Agents still privately optimize such that private equilibrium is jointly determined by

$$
\begin{array}{r}
h^{\prime}\left(\hat{x_{g}^{t}}\right)=\tau+\tilde{V} f^{\prime}(\tilde{X}) \\
h^{\prime}\left(\hat{x_{u}^{t}}\right)=\tau+f^{\prime}(\tilde{X})
\end{array}
$$

By convexity of $h(\cdot), h^{\prime}\left(\hat{x_{g}^{t}}\right) \neq h^{\prime}\left(\hat{x_{u}^{t}}\right)$. Under a standard, all agents provide a minimum level of provision $\frac{\tilde{X}}{N}$ such that $h^{\prime}\left(\frac{\tilde{X}}{N}\right)>\tilde{V} f^{\prime}(\tilde{X})>f^{\prime}(\tilde{X})$. As a result, $\tilde{X}$ is provided such that $h^{\prime}\left(x_{i}\right)=h^{\prime}\left(x_{j}\right) \forall i, j$. By Proposition 2, a standard is a least cost mechanism for providing $\tilde{X}$ whereas by equations (13) and (14) a tax is not, giving the desired result.

Proposition 3: For any level of regulated public goods provision $\tilde{X}$ such that the standard 
binds for non-greens but not for green agents, $\hat{x_{g}} \geq \frac{\tilde{X}}{N} \geq \hat{x_{u}}$, a standard is always more efficient than a uniform price instrument.

PROOF: Equilibrium in the price instrument case is given by the system

$$
\begin{array}{r}
h^{\prime}\left(\hat{x_{g}^{t}}\right)=\tau+\tilde{V} f^{\prime}(\tilde{X}) \\
h^{\prime}\left(\hat{x_{u}^{t}}\right)=\tau+f^{\prime}(\tilde{X})
\end{array}
$$

By convexity of $h(\cdot), h^{\prime}\left(\hat{x_{g}^{t}}\right)>h^{\prime}\left(\hat{x_{u}^{t}}\right)$ and $x_{g}^{t}>x_{u}^{t}$. In the case of the standard, green agents' provision, $x_{g}^{s}$ is defined by their first order condition: $h^{\prime}\left(\hat{x_{g}^{s}}\right)=\tilde{V} f^{\prime}(\tilde{X})$. By convexity of $h(\cdot)$ and $\tau>0$, it implies $x_{g}^{t}>x_{g}^{s}$. Further, $\tilde{X}=N\left(\alpha x_{g}^{s}+(1-\alpha) x_{u}^{s}\right)$. As a result, non-green provision of the public good in the case of standards can be expressed as $x_{u}^{s}=$ $\frac{(\tilde{X} / N)-\alpha x_{g}^{s}}{1-\alpha}$. Since $x_{g}^{t}>x_{g}^{s}$, it implies $x_{u}^{s}>x_{u}^{t}$ and subsequently $x_{g}^{t}-x_{u}^{t}>x_{g}^{s}-x_{u}^{s}$.

Consider a case in which $x_{g}^{t}=x_{g}^{s}+\epsilon$ for $\epsilon>0$ to reach some $\tilde{X}$. Noting that the distribution of provision in the case of a standard would therefore be $\alpha N x_{g}^{s}+(1-\alpha) N\left(x_{u}^{t}+\right.$ $\frac{\alpha}{(1-\alpha} \epsilon$. The average cost of provision for $x$ across agents in the price instrument case is $p^{t}=\alpha h\left(x_{g}^{s}+\epsilon\right)+(1-\alpha) h\left(x_{u}^{t}\right)$ and in the case of subsidies is therefore $p^{s}=\alpha h\left(x_{g}^{s}\right)+(1-$ $\alpha) h\left(x_{u}^{t}+\frac{\alpha}{1-\alpha} \epsilon\right) \cdot p^{t}>p^{s}$ by concavity of $h(\cdot)$ giving the desired result.

Corollary 2: The provision of green agents in the case of price instruments, $x_{g}^{t}$, and the price instrument/subsidy needed to attain a given level of public good provision, $\tau$, are both always decreasing in the percentage of green agents, $\alpha$.

Equilibrium in the case of price instruments is given by equations (13) and (14) above in addition to the level constraint: $\tilde{X}=\alpha N x_{g}^{t}+(1-\alpha) N x_{u}^{t}$. Substituting a transformation of the constraint in for non-green agents provision, $x_{u}^{t}=\frac{(\tilde{X} / N)-\alpha x_{g}^{t}}{1-\alpha}$, leaves two equations and two unknowns. Cramer's Rule states that

$$
\frac{d x_{g}^{t}}{d \alpha}=\frac{\left|\Lambda_{1, \alpha}\right|}{|H|}, \quad \frac{d \tau}{d \alpha}=\frac{\left|\Lambda_{2, \tau}\right|}{|H|}
$$


Where $H$ is the hessian of the system and $\Lambda_{n, \phi}$ is the hessian with the $n^{\text {th }}$ column replaced with the negatives of the first order condition derivatives with respect to the parameter $\phi$.

$$
H=\left(\begin{array}{cc}
\frac{\partial F O C_{g}}{\partial x_{g}^{t}} & \frac{\partial F O C_{g}}{\partial \tau} \\
\frac{\partial F O C_{u}}{\partial x_{g}^{t}} & \frac{\partial F O C_{u}}{\partial \tau}
\end{array}\right)=\left(\begin{array}{cc}
-h^{\prime \prime}\left(x_{g}^{t}\right) & 1 \\
h^{\prime \prime}\left(x_{g}^{t}\right) \frac{\alpha}{1-\alpha} & 1
\end{array}\right)
$$

By inspection, the determinant of the hessian $H$ is negative. Further, $\Lambda_{1, \alpha}$ and $\Lambda_{2, \tau}$ are respectively

$$
\Lambda_{1, \alpha}=\left(\begin{array}{cc}
0 & 1 \\
h^{\prime \prime}\left(x_{g}^{t}\right) \frac{(\tilde{X} / N)-x_{g}^{t}}{(1-\alpha)^{2}} & 1
\end{array}\right) \quad \Lambda_{2, \tau}=\left(\begin{array}{cc}
-h^{\prime \prime}\left(x_{g}^{t}\right) & 0 \\
h^{\prime \prime}\left(x_{g}^{t}\right) \frac{\alpha}{1-\alpha} & h^{\prime \prime}\left(x_{g}^{t}\right) \frac{(\tilde{X} / N)-x_{g}^{t}}{(1-\alpha)^{2}}
\end{array}\right)
$$

Noting that $\tilde{X} / N<x_{g}^{t}$ by Proposition 4, by inspection $\left|\Lambda_{1, \alpha}\right|>0$ and $\left|\Lambda_{2, \tau}\right|>0$ implying that $\frac{d x_{g}^{t}}{d \alpha}<0$ and $\frac{d \tau}{d \alpha}<0$ giving the desired result.

Corollary 3: The provision of green agents in the case of price instruments, $x_{g}^{t}$, is increasing and the price instrument/subsidy needed to attain a given level of public good provision, $\tau$, is decreasing in the strength of the green preference, $\tilde{V}$.

Equilibrium in the case of price instruments is given by equations (13) and (14) above in addition to the level constraint: $\tilde{X}=\alpha N x_{g}^{t}+(1-\alpha) N x_{u}^{t}$. Substituting a transformation of the constraint in for non-green agents provision, $x_{u}^{t}=\frac{(\tilde{X} / N)-\alpha x_{g}^{t}}{1-\alpha}$, leaves two equations and two unknowns. Cramer's Rule states that

$$
\frac{d x_{g}^{t}}{d \tilde{V}}=\frac{\left|\Lambda_{1, \tilde{V}}\right|}{|H|}, \quad \frac{d \tau}{d \tilde{V}}=\frac{\left|\Lambda_{2, \tilde{V}}\right|}{|H|},
$$

Where $H$ is the hessian of the system and $\Lambda_{n, \phi}$ is the hessian with the $n^{\text {th }}$ column replaced with the negatives of the first order condition derivatives with respect to the parameter $\phi$. By Corollary 2, $|H|<0$. Further $\left|\Lambda_{1, \tilde{V}}\right|$ and $\left|\Lambda_{2, \tilde{V}}\right|$ are defined as 


$$
\Lambda_{1, \tilde{V}}=\left(\begin{array}{cc}
-f^{\prime}(\tilde{X}) & 1 \\
0 & 1
\end{array}\right) \quad \Lambda_{2, \tilde{V}}=\left(\begin{array}{cc}
-h^{\prime \prime}\left(x_{g}^{t}\right) & -f^{\prime}(\tilde{X}) \\
h^{\prime \prime}\left(x_{g}^{t}\right) \frac{\alpha}{1-\alpha} & 0
\end{array}\right)
$$

By inspection, $\left|\Lambda_{1, \tilde{V}}\right|<0$ and $\left|\Lambda_{2, \tilde{V}}\right|>0$. Therefore $\frac{d x_{g}^{t}}{d \tilde{V}}>0$ and $\frac{d \tau}{d \tilde{V}}<0$ giving the desired result.

Proposition 4: For any level of regulated public goods provision $\tilde{X}$ such that the standard binds of all agents, $\frac{\tilde{X}}{N} \geq \hat{x_{g}}$, the difference in welfare between the two policies, $\Delta_{t s}$, is single peaked in the percentage of green agents, $\alpha$.

This proof proceeds by construction. We first show that the limit of the total derivative of the difference, $\Delta_{t s}$, is positive as $\alpha \rightarrow 0^{+}$and negative as $\alpha \rightarrow 1^{-}$. We then show that the partial derivative of the difference between the policies, $\Delta_{t s}$, is positive. We can define $\Delta_{t s}$ as

$$
\Delta_{t s}=\alpha N \int_{\frac{\tilde{X}}{N}}^{x_{g}^{t}} h^{\prime}(x) d x-(1-\alpha) N \int_{x_{u}^{t}=\frac{\frac{\tilde{X}}{N}-\alpha N}{1-\alpha}}^{\frac{\tilde{X}}{N}} h^{\prime}(x) d x
$$

The total derivative of equation (22) can be found using Leibniz Rule:

$$
\begin{array}{r}
\frac{d \Delta_{t s}}{d \alpha}=N \int_{\frac{\tilde{X}}{N}}^{x_{g}^{t}} h^{\prime}(x) d x+\alpha N\left(M h^{\prime}\left(x_{g}^{t}\right)\right)+N \int_{x_{u}^{t}=\frac{\tilde{X}}{N}-\alpha N}^{\frac{\tilde{X}}{N}} h^{\prime}(x) d x \\
-(1-\alpha) N\left(-M \frac{(\tilde{X} / N)-x_{g}^{t}}{(1-\alpha)^{2}} h^{\prime}\left(\frac{(\tilde{X} / N)-\alpha x_{g}^{t}}{1-\alpha}\right)\right) \\
M \equiv \frac{\left(h^{\prime \prime}\left(x_{u}^{t}\right) \frac{\tilde{X}}{N}-x_{g}^{t}\right) /\left((1-\alpha)^{2}\right)}{h^{\prime \prime}\left(x_{g}^{t}\right)+\frac{\alpha}{1-\alpha} h^{\prime \prime}\left(x_{u}^{t}\right)}
\end{array}
$$

Note that $M<0$ for any $\alpha$ and consider $\lim _{\alpha \rightarrow 0^{+}}$. The terms with the intergrals converge to zero leaving only the terms multipling $M$. The first term goes to zero and by Proposition 4, the second term is positive signing $\lim _{\alpha \rightarrow 0^{+}}>0$. Similarly, $\lim _{\alpha \rightarrow 1^{-}}$is sign by the first term multiplying $M$ which is positive signing $\lim _{\alpha \rightarrow 1^{-}}<0$. Finally, the partial derivative of $\Delta_{t s}$ is 


$$
\frac{\partial \Delta_{t s}}{\partial \alpha}=N \int_{\frac{\tilde{X}}{N}}^{x_{g}^{t}} h^{\prime}(x) d x+N \int_{x_{u}^{t}=\frac{\frac{\tilde{X}}{N}-\alpha N}{1-\alpha}}^{\frac{\tilde{X}}{N}} h^{\prime}(x) d x-(1-\alpha) N\left(-M \frac{(\tilde{X} / N)-x_{g}^{t}}{(1-\alpha)^{2}} h^{\prime}\left(\frac{(\tilde{X} / N)-\alpha x_{g}^{t}}{1-\alpha}\right)\right)
$$

By inspection, equation (25) is positive completing the proof.

Corollary 4: For any level of regulated public goods provision $\tilde{X}$ such that the standard binds for all agents, $\frac{\tilde{X}}{N} \geq \hat{x_{g}}$, the difference in welfare between the two policies, $\Delta_{t s}$, is always increasing in the strength of the green preference, $\tilde{V}$.

This proof proceeds by construction. We show that the total derivative of the difference, $\Delta_{t s}$, is everywhere greater than zero. Again using Leibniz rule and simplying we find

$$
\frac{d \Delta_{t s}}{d \tilde{V}}=\alpha N \frac{d x_{g}^{t}}{d \tilde{V}}\left(h^{\prime}\left(x_{g}^{t}\right)-h^{\prime}\left(\frac{\frac{\tilde{X}}{N}-\alpha N}{1-\alpha}\right)\right)
$$

By Proposition 4, Corollary 3, and convexity of $h(\cdot)$, equation (26) is positive, giving the desired result.

Proposition 5: There is an asymmetric price instrument which leads to efficient provision of any level of the public good, $\tilde{X}$. Under such a policy, the subsidy for non-greens, $\tau_{u}$, is strictly larger than the subsidy for greens, $\tau_{g}$.

PROOF: There are four conditions which must be jointly satisfied in order to have efficient public good provision with an asymmetric price instrument profile. By Propisition 1 and Proposition 2, these conditions are 


$$
\begin{aligned}
h^{\prime}\left(x_{g}^{t}\right) & =\tau_{g}+\tilde{V} f^{\prime}(\tilde{X}) \\
h^{\prime}\left(x_{u}^{t}\right) & =\tau_{u}+f^{\prime}(\tilde{X}) \\
\tilde{X} & =\alpha N x_{g}^{t}+(1-\alpha) N x_{u}^{t} \\
h^{\prime}\left(x_{g}^{t}\right) & =h^{\prime}\left(x_{u}^{t}\right)
\end{aligned}
$$

Substituting in, we get the condition $\tilde{V} f^{\prime}(\tilde{X})+\tau_{g}=f^{\prime}(\tilde{X})+\tau_{u}$. Rearranging gives $(V-1) f^{\prime}(\tilde{X})=\tau_{u}-\tau_{g}$. By assumption, $V>1$ and $f^{\prime}(\cdot)>0$ giving the desired result.

Proposition 6: With asymmetric costs, the amount of public good provided by greens is inversely related to their relative cost position. The (uniform) subsidy needed to reach any level of public goods provision is increasing in the relative marginal cost of provision for green agents.

PROOF: This proof proceeds by construction and is similar to Corollary 2. Using the same notation as in Corollary 2:

$$
\frac{d x_{g}^{t}}{d \delta}=\frac{\left|\Lambda_{1, \alpha}\right|}{|H|}, \quad \frac{d \tau}{d \delta}=\frac{\left|\Lambda_{2, \tau}\right|}{|H|}
$$

These matrices are defined as:

$$
H=\left(\begin{array}{cc}
\frac{\partial F O C_{g}}{\partial x_{g}^{t}} & \frac{\partial F O C_{g}}{\partial \tau} \\
\frac{\partial F O C_{u}}{\partial x_{g}^{t}} & \frac{\partial F O C_{u}}{\partial \tau}
\end{array}\right)=\left(\begin{array}{cc}
-h^{\prime \prime}\left(x_{g}^{t}\right) \delta & 1 \\
h^{\prime \prime}\left(x_{g}^{t}\right) \frac{\alpha}{1-\alpha} & 1
\end{array}\right)
$$

By inspection, the determinant of the hessian $H$ is negative. Further, $\Lambda_{1, \delta}$ and $\Lambda_{2, \delta}$ are respectively

$$
\Lambda_{1, \delta}=\left(\begin{array}{cc}
-h^{\prime}\left(x_{g}^{t}\right) & 1 \\
0 & 1
\end{array}\right) \quad \Lambda_{2, \delta}=\left(\begin{array}{cc}
-h^{\prime \prime}\left(x_{g}^{t}\right) \delta & -h^{\prime}\left(x_{g}^{t}\right) \\
h^{\prime \prime}\left(x_{g}^{t}\right) \frac{\alpha}{1-\alpha} & 0
\end{array}\right)
$$

By inspection, the determinants of $\Lambda_{1, \delta}$ and $\Lambda_{2, \delta}$ are positive and negative respectively. 
As a result, using Cramer's rule, $\frac{d x_{g}^{t}}{d \delta}<0$ and $\frac{d \tau}{d \delta}>0$ giving the desired result.

Proposition 7: With asymmetric costs, the relative efficiency of a uniform price instrument vis-a-vis a standard is greater when the costs for green agents are negatively correlated with the strength of their green preferences. subject to one regularity condition

PROOF: We can define the equation (22) analog very for this model as

$$
\Delta_{t s}=\alpha N(1+\delta) \int_{\frac{\tilde{X}}{N}}^{x_{g}^{t}} h^{\prime}(x) d x-(1-\alpha) N \int_{x_{u}^{t}=\frac{\frac{\tilde{X}}{N}-\alpha x_{g}^{t}}{1-\alpha}}^{\frac{\tilde{X}}{N}} h^{\prime}(x) d x
$$

By inspection, $\frac{\partial \Delta_{t s}}{\partial \delta}>0$. However, accounting for indirect effects as in Proposition 5 we take the total derivative use Leibnitz rule:

$$
\frac{d \Delta_{t s}}{d \delta}=\alpha N \int_{\frac{\tilde{X}}{N}}^{x_{g}^{t}} h^{\prime}(x) d x+\alpha N \frac{d x_{g}^{t}}{d \delta}\left(h^{\prime}\left(x_{g}^{t}\right)-h^{\prime}\left(x_{u}^{t}\right)+\delta h^{\prime}\left(x_{g}^{t}\right)\right)
$$

By inspection, the direct effect is still positive but the indirect effect operates in the other direction since $\frac{d x_{g}^{t}}{d \delta}<0$ from Proposition 7 . The net effect, though is still positive as long as

$$
\frac{h\left(x_{g}^{t}\right)-h\left(\frac{\tilde{X}}{N}\right)}{-\frac{d x_{g}^{t}}{d \delta} h^{\prime}\left(x_{g}^{t}\right)}>1+\delta .
$$

This is a regularity condition ensuring that the green agents do not have a marginal cost of abatement curve that is so high they provide less of the public good than non-green agents. This concludes the proof.

\section{Appendix B}

This appendix shows equivalence between the model used in this paper and a model with a linear budget constraint but decreasing marginal utility with respect to the private good. 
The utility and budget specification in this paper are represented as

$$
\begin{aligned}
U_{i}\left(c_{i}, X \mid \Theta\right)= & c_{i}+\tilde{V} f_{i}(X) \\
& \text { s.t. } y_{i}=c_{i}+h\left(x_{i}\right) \\
\Rightarrow U_{i}\left(c_{i}, X \mid \Theta\right)= & y_{i}-h\left(x_{i}\right)+\tilde{V} f_{i}(X)
\end{aligned}
$$

As shown above, the first order condition of the consumer's problem is

$$
\left.\left.h_{i}^{\prime *}\right) \geq \tilde{V} f^{\prime *}\right) \forall i
$$

The function $h_{i}^{\prime *}$ ) is the first derivative of a convex function.

It is possible to use a linear budget constraint with decreasing marginal utility of the numeraire consumption good. Assume that utility derived from the numeraire consumption good is described by a concave function $\nu(c), \nu^{\prime}(c)>0$, and $\nu^{\prime \prime}(c)<0$. The consumer's choice problem can then be expressed as

$$
\begin{array}{rr}
U_{i}\left(c_{i}, X \mid \Theta\right)= & \nu\left(c_{i}\right)+\tilde{V} f_{i}(X) \\
& \text { s.t. } y_{i}=c_{i}+p_{x} x_{i} \\
\Rightarrow U_{i}\left(c_{i}, X \mid \Theta\right)= & \nu\left(y_{i}-p_{x} x_{i}\right)+\tilde{V} f_{i}(X)
\end{array}
$$

Now consider the private equilibrium of the consumer given the model in equation (34). The consumer's first order condition is

$$
-p_{x} \nu^{\prime}\left(y_{i}-p_{x} x_{i}\right) \geq \tilde{V} f_{i}^{\prime}(X)
$$

with equality if $x_{i}>0$. The left hand side of the consumer's first order condition in equation (35) is the opportunity cost of spending additional resources on purchase of the public good. Specifically, $-p_{x} \nu^{\prime}\left(y_{i}-p_{x} x_{i}\right)$ can be evaluated as a function of $x_{i}$ in equilibrium as opposed to a function of $c_{i}$. If $\nu\left(c_{i}\right)$ is concave and increasing in $c_{i}$ then by definition 
it is concave and decreasing in $x_{i}$. Further, $-p_{x} \nu^{\prime}\left(y_{i}-p_{x} x_{i}\right)$ is increasing in $x_{i}$. Figure 6 shows this relationship visually.

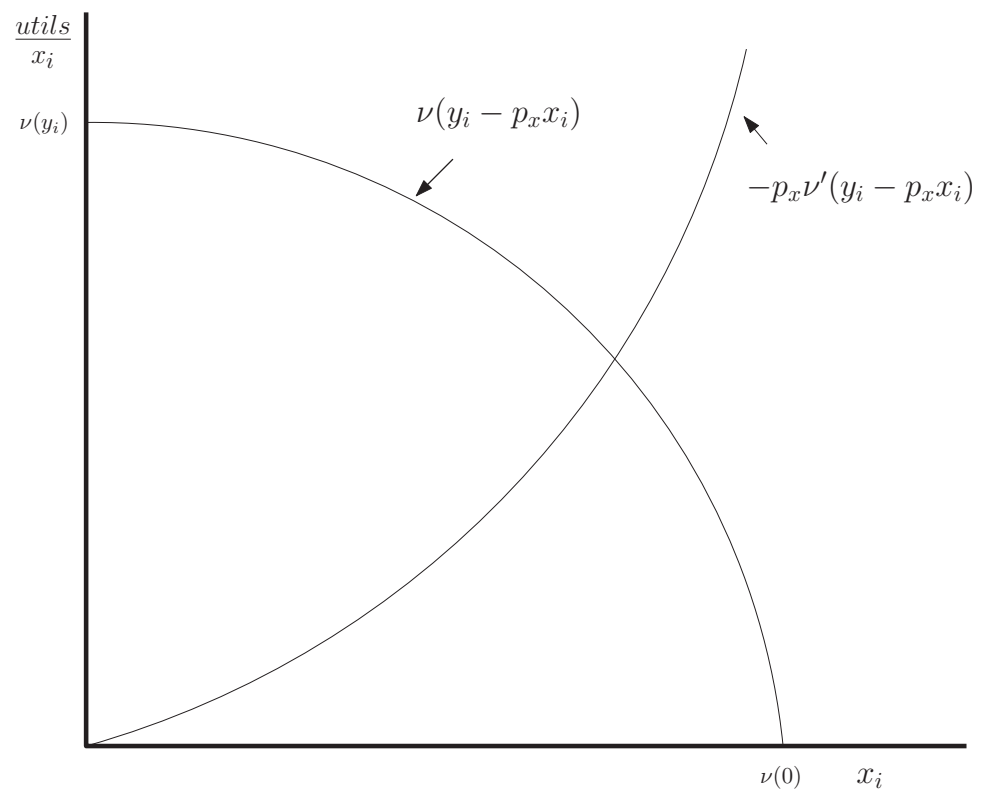

Figure 6: Equivalence of Alternative Utility Specification

Importantly, the left hand side of equations (33) and (35) are both increasing functions of the arguments $x_{i}$. As a result, equilibrium in these models will be equivalent. For example, the proof of Proposition 1 under this alternative specification is as follows:

Proposition 1: Green agents always provide more of the public good than non-green agents.

PROOF: By definition, $\tilde{V}$ is strictly larger for greens than non-greens. Private equilibrium provision for greens, $\hat{x_{g}}$, and non-greens, $\hat{x_{u}}$, are implicitly defined by the following system of equations:

$$
\begin{array}{r}
-p_{x} \nu^{\prime}\left(y_{i}-p_{x} \hat{x_{g}}\right)=\tilde{V} f^{\prime}\left(\alpha N \hat{x_{g}}+(1-\alpha) N \hat{x_{u}}\right) \\
-p_{x} \nu^{\prime}\left(y_{i}-p_{x} \hat{x_{u}}\right)=f^{\prime}\left(\alpha N \hat{x_{g}}+(1-\alpha) N \hat{x_{u}}\right)
\end{array}
$$


Since $\tilde{V}>1$ it must be that $\hat{x_{g}}>\hat{x_{u}}$ since $-p_{x} \nu^{\prime}\left(y_{i}-p_{x} \hat{x_{g}}\right)$ is increasing in $x_{i}$ giving the desired result. 